\title{
Cross-Country Predictive Validities of Non-cognitive Variables for Mathematics Achievement: Evidence based on TIMSS 2015
}

\author{
Jihyun Lee ${ }^{1 *}$, Minge Chen ${ }^{2}$ \\ ${ }^{1}$ Associate Professor, School of Education, University of New South Wales, Sydney, AUSTRALIA \\ ${ }^{2}$ Research Analyst, Research, Analysis \& Sampling Unit, the International Association for the Evaluation of Educational \\ Achievement (IEA), Hamburg, GERMANY
}

Received 2 April 2018 • Revised 21 March 2019 • Accepted 25 March 2019

\begin{abstract}
This study presents empirical findings demonstrating predictive validities of noncognitive variables for mathematics achievement among primary and secondary school students from cross-country perspectives. Results based on TIMSS 2015 assessment showed that confidence was a moderately strong predictor of mathematics achievement in all TIMSS participant countries (100\%). Interest, on the other hand, was a moderately strong predictor in most countries for eighth-graders (77\%) but only in about a dozen countries for fourth-graders $(20 \%)$, showing a stronger interestachievement link for the secondary school students, from the cross-national perspective. The sense of belonging measure demonstrated a lack of its relevance to primary school students' achievement. Further, bullying showed predictive relevance for student achievement only in three countries (South Africa, Jordan, and Egypt). The study concludes that while confidence was a universally relevant predictor of student achievement across all countries/regions, predictive utilities of interest, sense of belonging, and bullying appeared to be heavily dependent on a grade-level and country/regional context.
\end{abstract}

Keywords: confidence, self-efficacy, interest, sense of belonging, bullying

\section{INTRODUCTION}

International large-scale assessments routinely collect data about students' non-cognitive characteristics to provide information about factors associated with academic achievement. The present study aimed to examine predictive validities of four non-cognitive variables that were measured in the most recent Trends in International Mathematics and Science Study (TIMSS) assessment conducted by the International Association for the Evaluation of Educational Achievement's (IEA). It examined whether the non-cognitive constructs that have been regularly collected in the large-scale assessment such as TIMSS had universal relevance as predictors of student achievement in mathematics. Specifically, the investigation was focused on whether a greater level of predictive validity of noncognitive constructs were shown in particular countries or regions, and how they might differ between samples of primary and secondary school students across a wide range of countries and regional/cultural groups.

In recent years scholars synthesized a host of non-cognitive variables with respect to their predictive utilities for student achievement (e.g., Hattie, 2009; Lee \& Shute, 2010; Lee \& Stankov, 2018; Richardson, Abraham, \& Bond, 2012). For instance, Lee and Stankov (2018) examined 65 non-cognitive variables and concluded that, self-efficacy, confidence, and educational aspiration had the best predictive validities for student achievement across TIMSS and PISA (Programmed for International Students Assessment) databases. A meta-analysis of Richardson et al. (2012), after analyzing 50 conceptually distinct non-cognitive variables, established that performance self-efficacy, academic self-efficacy, effort regulation, and grade-goal setting had the strongest predictabilities of academic performance measured in grade point average (GPA) among university students. Hattie's (2009) review highlighted motivation/engagement, self-concept, anxiety, and attitudes towards mathematics as showing the strongest predictive validity of student achievement.

(c) 2019 by the authors; licensee Modestum Ltd., UK. This article is an open access article distributed under the terms and conditions of the Creative Commons Attribution License (http://creativecommons.org/licenses/by/4.0/). \jihyun.lee@unsw.edu.au (*Correspondence) $₫$ minge.chen@iea-hamburg.de 


\section{Contribution of this paper to the literature}

- Confidence was the best predictor of mathematics achievement across 63 countries, at both primary and secondary school levels.

- Interest showed the stronger relationship to mathematics achievement in the secondary school level than in the primary school level.

- Sense of belonging and bullying were not particularly good predictors of mathematics achievement in most countries.

The past review papers appear to suggest that self-beliefs have the best predictive validities for student achievement across different data bases and assessment schemes and across different grade and age levels. What has not been sufficiently examined is potential differential predictabilities of non-cognitive constructs across countries, cultures, and world regions, and between primary and secondary school students within and across particular countries. Even studies that utilized large-scale international databases have not devoted a great deal of attention to cross-county applicability and relevance of non-cognitive constructs.

Variable selection of the present study was guided by two main sources: previous studies that reported empirical evidence of predictive validities over a vast number of non-cognitive constructs (Hattie, 2009; Lee \& Stankov, 2018; Richardson et al., 2012), and a conceptual framework compiled over 115 unique non-cognitive constructs, called the Personal and Social Contextual Factors (PSCF), proposed in Lee and Shute (2010). The PSCF framework classified non-cognitive constructs into four major domains of student engagement, learning strategies, school climate, and family influences. The first two were students' personal characteristics (i.e., attitudinal, motivational, and behavioral) and the latter two were social-contextual circumstance factors (mainly related to school climate). Lee and Shute (2010) argues that while the predictive validities are stronger in students' personal characteristics, that does not mean that incremental validities from the social-contextual factors can be ignored because both personal and school contexts need to be considered simultaneously to gain a more complete understanding of student behaviors, intention, motivation and school outcomes. Further, McGill, Decker, McKlin, and Haynie (2019) highlights the importance of student engagement and school climate, because they are deemed "softer", more malleable to change, relatively easier to design school intervention programs, and showing better intervention outcomes in program evaluations.

In this study, we examined four non-cognitive constructs: confidence, intrinsic motivation/interest, sense of belonging, and bullying. Considering the past research mentioned above, self-belief constructs of confidence, selfefficacy, and self-concept were the first choice to be examined for cross-country validity (see Lee \& Stankov, 2018; Richardson et al., 2012), due to their strong predictive validity. The second construct was motivation, especially intrinsic motivation or labelled as interest (e.g., Deci \& Ryan, 1985), due to its strongest effect size for predicting student achievement in Hattie's (2009) mega-analysis over more than 800 meta-analytic studies. Based on the PSCF framework (Lee \& Shute, 2010) and McGill et al. (2019), the school climate factor expressed in sense of belonging and bullying was also considered in the present study as an important dimension of students' social environment that could affect academic performance. In the following sections, each of the four non-cognitive variables and their relationships to students' achievement were briefly outlined.

\section{CONFIDENCE AND ACADEMIC ACHIEVEMENT}

There have been three lines of scholarly work on confidence, i.e., how confidently people think and feel about their own abilities, with three different terms: self-efficacy led by Bandura (1989; 2012), self-concept led by Marsh (e.g., Marsh \& Craven, 2006; Marsh \& Shavelson, 1985), and confidence led by Stankov (Stankov \& Crawford, 1997; Stankov \& Lee, 2015). Self-efficacy is often defined as a person's belief about completing a task in spite of challenges and difficulties one may face (Bandura, 1989; 2012). Self-concept is akin to self-identity, i.e., thinking and believing that a person is good at doing things (mathematics, swimming, e.g., Marsh \& Craven, 2006). Confidence in the work of Stankov is defined as a subjective feeling and judgement about the correctness of one's course of action and decision (Stankov \& Lee, 2015). The nature and psychological utilities as well as measurement issues surrounding these three constructs in relation to student achievement have been heavily debated over the past decades (see Bong \& Skaalvik, 2003; Stankov \& Lee, 2015). The most discussed issue has been whether typical methods might have affected their predictive validities of student achievement (Stankov \& Lee, 2015).

In the context of international large-scale assessments, both self-concept and self-efficacy are usually measured on a Likert-type response scale presented in a questionnaire format. The self-concept scale items in both TIMSS and PISA asked the students how they thought about themselves in doing mathematics. The self-efficacy scale items in PISA asked how confident they were in solving a series of specific mathematics tasks (e.g., solving an equation like $3 x+5=17)$. On the other hand, much of recent studies that compared predictive utilities of non-cognitive constructs 
involving the three self-beliefs constructs were conducted by Stankov and his associates (Stankov \& Lee, 2014; 2015; 2016; 2017). Test-takers would be asked to solve a cognitive/academic item first and then rate their confidence (using a percentage scale) to indicate how well they think they did on the item they have just solved. Measured in this way, confidence showed the best predictive validity among the three self-beliefs, demonstrating a typical correlation of up to $r=.60$, and this method has been used and validated across more than 30 countries (see Stankov \& Lee, 2014; 2015; 2016; 2017). Bandura's self-efficacy typically shows the predictability up to about $r=.40$ s, while Marsh's self-concept demonstrated its predictability typically falling at around $r=$ mid .20 s (see Stankov \& Lee, 2014 for summary of predictive validities of these three variables).

In the present study TIMSS' confidence scale was employed to utilize the rich contextual information and assessment database across more than 60 countries at two grade-levels. TIMSS's confidence scale is in fact a measure of self-concept in terms of its notion, measurement method, and scale items, but its official scale name is confidence (see Martin, Mullis, \& Hooper, 2016), which was kept in the present study for consistency with the label in the publicly available database. Conceptually, the question is whether the TIMSS confidence scale would emulate the predictability levels that have been shown in the three lines of self-beliefs research mentioned above, crossnationally and from developmental perspectives, i.e., whether the confidence-achievement relationship would hold for primary and secondary school students. To the best of our knowledge, no previous studies have examined the confidence-achievement relationships of primary and secondary school students based on the same instruments under the same assessment scheme across more than 60 countries.

\section{INTEREST AND ACADEMIC ACHIEVEMENT}

Students' interest in learning is regarded to be a driving force behind their academic engagement and school achievement. In much of the motivation research, interest is operationalized as intrinsic motivation, i.e., doing things for the sake of pleasure and enjoyment (Krapp, 1999). Students having higher intrinsic motivation participate in learning activities more frequently, set more personal goals for learning, and engage themselves in various types of opportunity to learn (e.g., Putro \& Lee, 2017; Vansteenkiste, Lens, \& Deci, 2006). Interest in academic subjects has been linked to young students' perspectives on their career choice and planning, aspiration for further education, and a general outlook on and confidence about their future (Lee \& Durksen, 2018).

It has also been known that students' interest in academic domains is relatively stable from elementary through high school years and becomes increasingly stable as students grow older (Gottfried, Fleming, \& Gottfried, 2001). The rates of the increase in the strength of the relationship went up until the $10^{\text {th-grade }}$ and then slightly flattened during the final two years of secondary schooling. In spite of the leveling off, the strongest link between interest and achievement was still found in the final year of the secondary school (Denissen, Zarrett, \& Eccles, 2007). These studies suggest that younger students' academic interest may be nurtured and supported in earlier, primary school days, because interventions to increase students' interest at the secondary school level may not be as effective due to the established self-identity as a student.

Whether previous research findings on interest would hold for students across countries is relatively unknown because cross-country validation studies on the interest-achievement relationships have been rare. On the other hand, similar constructs, self-concept (e.g., Marsh \& Hau, 2004), academic emotions (e.g., Frenzel, Thrash, Pekrun, \& Goetz, 2007), and mathematics anxiety (Lee, 2009), have attracted a great deal of attention for cross-country validation. One cross-national finding has been East Asian students' substantially lower enthusiasm for learning, compared to the students in other countries. East Asian students showed relative lack of enjoyment in learning, feeling anxious about their academic outcomes, and having low self-concept in mathematics (Lee, 2009). The present study, by investigating the interest-achievement relationships across more than 60 countries, sheds light on cross-country validations of the interest-achievement relationships.

\section{SENSE OF BELONGING AND ACADEMIC ACHIEVEMENT}

Students' sense of belonging is often researched under a broader concept of school climate, representing quality of interpersonal relationships and connectedness among peers as well as with teachers, staff, and school affiliation (Wang \& Degol, 2016). Students with strong sense of belonging would be more active in building peer networks and friendships (Gifford-Smith \& Brownell, 2003), receiving social support from teachers and peers (Wentzel, 1994), and seeking peer or teacher help for school work (Fuller-Rowell \& Doan, 2010). A good sense of belonging at school leads to perceived social acceptance, a psychological condition that may be necessary to prevent school drop-out and develop positive classroom behaviors conducive to learning and school achievement (e.g., Chen, Rubin, \& Li, 1997; Wang \& Degol, 2016; Wentzel, 1994).

Sense of belonging at school may be particularly important during adolescence when youth begin to explore their self-identity (Baumeister \& Leary, 1995; Lee \& Durksen, 2018). In this sense, it is possible that sense of belonging may be a more relevant construct for teenagers than younger primary school children. An alternative 
view has been proposed that young children's school lives may be more affected by the relationship aspects, through parental involvement with schools and teachers (Sheldon, 2003), as teenagers would have learned to form and value relationships outside of school.

Researchers have made cultural and racial ramifications of sense of belonging with respect to friendship formation among peers within/outside the perceived racial/ethnic identity (Fuller-Rowell \& Doan, 2010; Mattison \& Aber, 2007; Wang \& Hugely, 2012). Most of the studies, however, have been conducted in the Western-Anglo background and English-speaking country contexts, and cross-cultural aspects have been limited to racial/ethnic backgrounds of one country context (typically in the US). It is still an open question whether and how strongly sense of belonging would exert its influence on student achievement across countries/regions.

\section{BULLYING AND ACADEMIC ACHIEVEMENT}

Bullying at school is an unfriendly or threatening behavior initiated by one or more students toward a student who is seen as being relatively weaker physically or psychologically and unable to defend him/herself (Olweus, 1993; Roland \& Galloway, 2004). Bullying incidents at school tend to be underreported and consequently, longstanding bullying episodes could have detrimental effects on the victims' social and academic functioning at school (Schwartz, Gorman, Nakamoto, \& Toblin, 2005). Victims of bullying may have difficulties in coping and social-emotional adjustment, which is often manifested in anxiety, depression, loneliness, psychological distress, and low self-esteem (Craig, 1998; Roland \& Galloway, 2004). Victims of bullying are also at risk of developing externalizing behavioral problems such as aggression, impulsiveness, hyperactivity, and adjustment anxiety (Schwartz et al., 2005).

In spite of the intuition that bullying experiences can affect academic functioning at school, a number of empirical studies on the bullying and academic achievement have been less than compelling (e.g., Juvonen, Nixhina, \& Graham, 2000; Schwartz et al., 2005). For example, Schwartz et al. (2005) recruited third and fourthgrade students in the Los Angeles area and monitored them over a one-year period with two periods of data collection. The reported bivariate correlations between bullying victimization and test results ranged from $r=-.02$ to -.43 , depending on the sources of the bullying reporting (peer vs. teacher), types of bullying (overt-physical vs. social-relational bullying), types of assessment tasks (classroom vs. standardized test), and subject domains (mathematics vs. reading). While the bullying effects were more detrimental on the classroom than standardized tests, no further systematic pattern was found to explain differential effect sizes. Further, the only strong effect was between victimization incidents at two time points (Schwartz et al., 2005), suggesting a chronic pattern of bullyvictimization, which can exert a longer-lasting effect on the victims' learning and social functioning at school.

Scholars have also suggested that the bullying issue may be best examined at the school level (e.g., Roland \& Galloway, 2004) because higher incidents of bullying may occur at schools located in certain neighborhoods, with lower socio-economic status (SES) family backgrounds and/or among students with less privileged household backgrounds within the same school (e.g., Roland \& Galloway, 2004). Whether the same argument can be made at the country-level (i.e., less wealthy countries having more bullying incidents) is relatively unknown, because bullying has not been systematically examined across a wide range of cultural/national groups. Bullying attracted attention from education researchers in the USA (e.g., Hoover, Oliver, \& Hazler, 1992), Australia (Rigby, 1997), Japan (Yoneyama \& Naito, 2003), and Norway (Olweus, 1993, 2005; Roland, 2000; Roland \& Galloway, 2004), but many empirical studies tend to be based on a single country. Further, past research has not systematically explored the bullying effect on achievement across different ages/grade levels. The present investigation is perhaps the first study to document the bullying-achievement relationships in a wide range of countries among students in two developmental stages, i.e., primary school children and mid-teenagers attending secondary schools.

\section{METHODS}

\section{Data and Participants}

The TIMSS 2015 international database that aimed to assess mathematics and science achievement as well as learning/teaching-related factors around the globe (Foy, 2017), was analyzed in this study at both fourth- and eighth-grade levels. Starting in 1995, it has been administered every four years with six cycles thus far $(1995,1999$, $2003,2007,2011$, and 2015). In TIMSS 20151, a total of 55 countries/regions and benchmarking partners $(\mathrm{N}=324,820)$

${ }^{1}$ TIMSS 2015 allowed variations of the grade levels that participated in the assessment based on the country specific curriculum and school entry-level policies. Norway chose to have their students in fifth and ninth grades to participate the TIMSS, which are better comparison groups with neighboring countries of Sweden and Finland. However, Norway also assessed students at the fourth-grade and eighth-grade as benchmark data. Botswana and South Africa also assessed ninth-grade to improve the alignment with their curricula and TIMSS assessment (see http:/ / timss2015.org/timss-2015/about-timss-2015/ for more detail 
Table 1. TIMSS 2015 Participant Countries by Regional/Cultural Dimensions

\begin{tabular}{llcl}
\hline World region & Fourth-grade & Eighth-grade \\
\hline 1. & Anglo & 7 & 8 \\
\hline 2. & Western Europe & 10 & 3 \\
\hline 3. & Eastern Europe & 12 & 5 \\
\hline 4. & Latin America & 3 & 2 \\
\hline 5. & Middle East & 11 & 13 \\
\hline 6. & Sub-Saharan Africa & 1 & 2 \\
\hline 7. & Southeast Asia & 1 & 2 \\
\hline 8. & Confucian Asia & 5 & 5 \\
\hline
\end{tabular}

Table 2. Means and Standard Deviations (in bracket) of the Study Variables

\begin{tabular}{lcc}
\hline Variables & Fourth-graders & Eighth-graders \\
\hline Confidence in mathematics & $9.96(1.89)$ & $9.83(2.02)$ \\
\hline Interest in mathematics & $9.97(1.76)$ & $9.72(1.86)$ \\
\hline Sense of belonging & $10.03(1.92)$ & $9.77(1.90)$ \\
\hline Being bullied at school & $9.95(1.94)$ & $9.80(1.88)$ \\
\hline Mathematics achievement & $504(80)$ & $471(84)$
\end{tabular}

Notes. The higher scores of confidence, interest, and sense of belonging mean the higher/more/greater level of confidence, interest, and sense of belonging. The higher score of bullying means the less frequent experiences of being bullying at school.

participated at the fourth-grade level (average age of 9.5 years old). There were 45 countries/regions and benchmarking partners $(\mathrm{N}=280,120)$ at the eighth-grade level (average age of 13.5 years old). Some countries ${ }^{2}$ participated only at the fourth-grade level (e.g., Finland, France, Germany, Indonesia, Serbia), while others participated only at the eighth-grade level (e.g., Egypt, Lebanon, Thailand).

In total, there were 63 countries/regions/benchmarking partners who participated in TIMSS 2015. Regional representation of the TIMSS 2015 participant countries were presented in Table 1. The countries were classified following the cultural dimensions and classification of the GLOBE study based on 62 countries (House, Hanges, Javidan, Dorfman, \& Gupta, 2004) while Latin, Germanic, and Scandinavian/Nordic European countries were grouped into the Western European group in our study. Three things are noted in the regional classification. First, the discrepancy in the number of participant countries from the fourth- to eighth-grade levels was mainly due to the Western and Eastern European countries that chose to participate only at the fourth-grade level. Second, the participation from Middle-Eastern region was the strongest. Third, there was a relative lack of country presence from Latin America, Africa, and South Asia.

Sample size requirement for TIMSS is 4,000 students and 150 schools per country. For each grade level, more than $50 \%$ of the students within each classroom of a school had to participate (Martin, et al., 2016). The data can be downloaded either from the International Association for the Evaluation of Educational Achievement (IEA) website http://www.iea.nl/data__or the TIMSS and PIRLS International Study Center website https:/ / timssandpirls.bc.edu/timss2015/international-database/.

\section{Variables and Scales}

In the TIMSS 2015 assessment scheme, only four non-cognitive variables: confidence in mathematics, interest in mathematics, ${ }^{3}$ sense of belonging to school, and experience of being bullied in school, were made into the contextual background scales (i.e., multiple items grouped together as an indicator of a variable) because they were proved to have good psychometric properties (e.g., Cronbach's reliability) and sufficient levels of cross-country construct invariance (through a series of principal components analysis) (see Martin, Mullis, \& Hooper, 2016). The analyses of the non-cognitive variables in this study were limited to these four scale-level variables because they were deemed psychometrically suitable to compare across all TIMSS participating countries. The scale level scores for each variable were published in the TIMSS 2015 public data base, which were used in the current study. Means and standard deviations of the study variables are presented in Table 2.

information for sampling composition). Along with Norway (Grade 4) and Norway (Grade 8), other benchmarking participants are Belgium (Flemish), Canada (Ontario), Canada (Quebec), United Arab Emirates (Abu Dhabi), United Arab Emirates (Dubai), and Argentina (Buenos Aires). In our study, we kept this sampling unit as a whole and did not combine them into a regional or country score to keep the sampling strategies intact and therefore representative of students within the sampling unit.

${ }^{2}$ In this paper, countries/regions/benchmarking partners are referred to as "country" for simplicity of presentation.

${ }^{3}$ The TIMSS assessment framework used the term "liking", but we referred it to "interest" because it was a more widely used term in educational psychology literature. 
Mathematics achievement scores. Students took a subset of mathematics items from a total list of items for TIMSS 2015. Since the accuracy of estimating the population parameters is affected by this approach, multiple imputation technique was adopted to arrive at estimates of mathematics performance (Martin et al., 2016). Customarily, five estimates, known as plausible values, were generated to account for the variance of student achievement estimates (Martin et al., 2016; further see TIMSS 2015 Assessment Frameworks for comprehensive illustration on the test design). All five plausible values of mathematics achievement were used in the analysis. The same analysis was performed for each set of plausible values and then, the average of the five estimates is obtained as the final estimate, a method recommended for TIMSS data analysis (see Martin et al., 2016).

Confidence in mathematics. A total of 9 statements were used in the TIMSS Student Questionnaire to collect information about students' confidence in mathematics (shortened as confidence). Example items are "I usually do well in mathematics", "I learn things quickly in mathematics", and "my teacher tells me I am good at mathematics". Cronbach' alpha estimates of the Students' Confidence in Mathematics (SCM) scale were over .80 for both fourthand eighth-graders in most of the participant countries (Martin et al., 2016). A higher score on the confidence scale indicates a higher level of confidence of student reporting (see Martin et al., 2016 for the scale construction; p.15.93 for fourth-graders and p. 15.208 for eighth-graders).

Interest in mathematics. Students' interest in mathematics (shortened as interest) was made into a contextual scale labelled Students Like Learning Mathematics (SLM), based on a total of 9 statements, such as "I enjoy learning mathematics", "I like to solve mathematics problems", and "I look forward to mathematics lessons" (Martin et al., 2016). Cronbach' alpha estimates were over 90 at both grades for most of the participant countries (Martin et al., 2016). A higher score on the interest scale indicates greater interest in mathematics (see Martin et al., 2016 for the scale construction; p.15.103 for fourth-graders and p. 15.238 for eighth-graders).

Sense of belonging to school. The contextual scale of Students' Sense of School Belonging (SSB) scale (shortened as sense of belonging) was created based on a total of 7 statements, such as "I like being in school", "I feel like I belong at this school", and "I learn a lot in school". Cronbach' alpha estimates were over 80 at both grades for most of the countries (Martin et al., 2016). A higher score of the sense of belonging scale indicates a stronger sense of school belonging (see Martin et al., 2016 for the scale construction; p.15.113 for fourth-graders and p. 15.253 for eighth-graders).

Experience in being bullied at school. Students' experience in being bullied at school (shortened as bullying) was measured using a total of 9 statements for fourth-graders such as "made fun of me or call me names", "made me do things I didn't want to do", and "threatened me", to create the Student Bullying (SB) scale. An additional statement of "posted embarrassing things about me online" was included in the eighth-grader scale. Cronbach' alpha estimates were over .80 at both grades for most of the countries (Martin et al., 2016). A higher score of the bulling scale indicates the students having experienced fewer incidences of being bullied at school (see Martin et al., 2016 for the scale construction; p.15.88 for fourth-graders and p. 15.188 for eighth-graders). Given how the bullying scale was constructed, a positive correlation with achievement was expected, i.e., the higher the bullying scale score was, the fewer incidences of being bullied and the higher student achievement.

\section{Statistical Analysis}

Pearson's correlation coefficients were calculated between the above-mentioned four non-cognitive indicators and mathematic achievement scores. We used a cutoff point of $r \geq .224$ to determine whether the correlation effect size is substantial enough, i.e., suggestive of at least a medium effect size. This cut-off point was based on the suggestion (see Babchishin \& Helmus, 2016; Rice \& Harris, 2005) that a lower than $5 \%$ of shared variance between two variables (approximately translating to a Cohen's medium effect size $d=0.45$ and a correlation coefficient $r=$ .224) would not be considered to be of importance.

The effect sizes were presented not only in the absolute term (by using the cutoff point), but also in a relative sense (i.e., in relation to other countries). That is, we counted the countries showing at least medium-effect sizes and rank-ordered the countries to gain further insight to comparative predictive validities across countries. Only the top and bottom five countries with the highest and lowest correlations are shown and discussed for efficient presentation.

Finally, multiple regression was conducted to demonstrate relative effects of each of the independent variables (the four non-cognitive variables) above and beyond the presence of other independent variables in the model to predict mathematics achievement. All analyses in this study were conducted using the IDB analyzer, a free software developed by IEA for large-scale data analysis to account for special measurement features of large-scale assessments, such as student weights and plausible values. 
Table 3. Number of Countries Showing at Least a Moderate Correlation $(r \geq .224)$ with Mathematic Achievement: TIMSS 2015

\begin{tabular}{lcccc}
\hline & \multicolumn{2}{c}{ Fourth-grade (55 countries) } & \multicolumn{2}{c}{ Eighth-grade (44 countries) } \\
\hline & Number of countries & Percentages & Number of countries & Percentages \\
\hline Confidence in mathematics & 55 & $100 \%$ & 44 & $100 \%$ \\
\hline Interest in mathematics & 11 & $20 \%$ & 34 & $77 \%$ \\
\hline Sense of belonging & 0 & $0 \%$ & 8 & $18 \%$ \\
\hline Being bullied at school & 2 & $4 \%$ & 2 & $5 \%$ \\
\hline
\end{tabular}

\section{RESULTS}

\section{Confidence in Mathematics and Mathematics Achievement}

Overall findings. The predictive power of confidence for students' mathematics achievement is clearly demonstrated in the number of countries showing an effect size greater than $r=.224$. Remarkably, all TIMSS participating countries, 55 countries at the fourth-grade (100\%) and 44 countries at the eight-grade (100\%), showed the moderately strong associations between confidence and mathematics achievement (Table 3). The country average correlations (i.e., calculated for each country and then averaged) were moderately strong at both fourthgrade $(r=.395)$ and eighth-grade $(r=.428)$ levels. Even in the countries where the lowest correlations were exhibited, the effect sizes were in the medium range: [fourth-grade $(r=.224)$ in Kazakhstan and eighth-grade $(r=$ .231) in Thailand]. Confidence appears to have a universal relevance as a predictor of student achievement, across all TIMSS participant countries (Table 3).

Country-specific findings. Countries with the five highest and five lowest correlations between confidence and mathematics achievement are presented in Table 4 (fourth-grade on the top half and eighth-grade on the bottom half). At the fourth-grade level, the top five countries were Korea, Netherlands, Portugal, Hungary, and Turkey. Except that three out of the five are European countries, they do not appear to have other similarities in terms of cultural, language, political, economic, or religious characteristics, or in terms of their overall standing in students' academic performance (high/low). On the other hand, there was a strong presence of Scandinavian countries (Norway and Sweden), along with Canada, showing the highest correlations between confidence and achievement at the eighth-grade level.

The countries showing the lowest correlations between confidence and achievement were mostly MiddleEastern, Southeast Asian, and African countries: Indonesia, Qatar, Saudi Arabia, Kuwait, and Kazakhstan in the fourth-grade level and Kuwait, Botswana, Kazakhstan, South Africa, and Thailand in the eighth-grade level. These findings may be indicative of the nature of self-confidence as a psychological construct that may be more relevant to students growing up in Western, individualistic (as opposed to collectivist) countries/cultures where feeling good about oneself and focusing on personal strength and confidence are more explicitly advocated, nurtured, and developed in their social norms.

Comparison between primary and secondary school students. The overall effect size of confidence was larger for the secondary school students, compared to that for the primary school students. The average within-country correlation was somewhat higher at the eighth-grade $(r=.428)$ than at the fourth-grade $(r=.395)$. The highest correlation observed across countries was also higher in the eighth-grade level $(r=.612)$ than in the fourth-grade level $(r=.541)$. The lowest correlation observed across countries was slightly higher at the eighth-grade level $(r=$ .231) than at the fourth-grade level $(r=.224)$. Thus, it appears that the role of confidence as a correlate of achievement becomes stronger as students spend more time and gain more experiences in schooling, moving from primary to secondary school level.

\section{Interest in Mathematics and Mathematics Achievement}

Overall findings. Interest showed a moderately strong predictive power for mathematics achievement $(r \geq .224)$ only in 11 out of 55 countries (20\%) at the fourth-grade level but in a larger number/percentage, i.e., 34 out of 44 countries (77\%) at the eighth-grade level (see Table 3). As can be seen, the predictive power of interest was not as "universal" as confidence. Further, the country averages of the correlations between interest and mathematics were rather modest at: $r=.185$ at the fourth-grade and $r=.276$ at the eighth-grade (Table 4). 
Table 4. Bivariate Pearson Correlations with Mathematics Achievement with Countries showing the Highest and Lowest Correlations: TIMSS 2015

\begin{tabular}{|c|c|c|c|c|c|c|c|}
\hline \multicolumn{2}{|c|}{ Confidence } & \multirow[t]{2}{*}{ Interest } & & \multicolumn{2}{|c|}{ Sense of Belonging } & \multicolumn{2}{|c|}{ Not being bullied } \\
\hline \multicolumn{7}{|c|}{ Fourth-grade } & \\
\hline Korea & .541 & Korea & .331 & Turkey & .217 & South Africa & .261 \\
\hline Netherlands & .523 & South Africa & .317 & Japan & .162 & Jordan & .224 \\
\hline Portugal & .494 & Japan & .303 & Hong Kong & .161 & Saudi Arabia & .221 \\
\hline Hungary & .493 & Portugal & .283 & South Africa & .160 & Turkey & .217 \\
\hline Turkey & .468 & Morocco & .282 & Chile & .149 & Bulgaria & .188 \\
\hline Average & .395 & Average & .185 & Average & .076 & Average & .113 \\
\hline Indonesia & .291 & Belgium & .097 & Czech Rep. & -.034 & Kuwait & .045 \\
\hline Qatar & .278 & Slovak Rep. & .075 & Serbia & -.035 & Belgium & .033 \\
\hline Saudi Arabia & .267 & Sweden & .069 & Poland & -.042 & Iran & .032 \\
\hline Kuwait & .256 & Argentina & .058 & Slovak Rep. & -.082 & Indonesia & .022 \\
\hline Kazakhstan & .224 & New Zealand & .051 & Iran & -.122 & Korea & -.019 \\
\hline \multicolumn{8}{|c|}{ Eighth-grade } \\
\hline Norway & .612 & Taipei & .427 & UAE & .295 & Egypt & .262 \\
\hline Sweden & .592 & Sweden & .402 & Australia & .289 & South Africa & .226 \\
\hline Canada & .546 & Norway & .397 & England & .269 & Lebanon & .170 \\
\hline Lithuania & .539 & Korea & .396 & Malta & .258 & Jordan & .155 \\
\hline Slovenia & .539 & Canada & .358 & Hong Kong & .233 & Malaysia & .151 \\
\hline Average & .428 & Average & .276 & Average & .133 & Average & .081 \\
\hline Kuwait & .300 & Kazakhstan & .182 & Iran & .020 & Chile & .020 \\
\hline Botswana & .254 & Argentina & .164 & Lithuania & .018 & Taipei & .015 \\
\hline Kazakhstan & .246 & Kuwait & .158 & Jordan & .002 & Korea & -.041 \\
\hline South Africa & .243 & Jordan & .157 & Turkey & -.011 & Japan & -.056 \\
\hline Thailand & .231 & South Africa & .077 & Morocco & -.016 & Hong Kong & -.083 \\
\hline
\end{tabular}

Notes. UAE = United Arab Emirates. Argentina data is based on Bueonos Aires. Belgium data is based on the Flemish area of the country.

Benchmark participants are not included in this table if their country participated in the TIMSS (e.g., Ontario area of Canada and Canada).

Country-specific findings. Looking at specific countries' correlations, there was a noticeable presence of Confucian Asian countries showing the highest correlations between interest and mathematics: Korea and Japan at the fourth-grade and Chinese Taipei and Korea at the eighth-grade. Scandinavian countries (Sweden and Norway) were also among the countries with the highest correlations between interest and mathematics at the eighth-grade level, as they were among the countries with the highest correlations between confidence and mathematics.

On the other end, the weakest and near zero correlations were shown by European countries of Belgium, Slovak Republic, and Sweden at the fourth-grade, and Middle East and African countries of Jordan, Kuwait, and South Africa at the eight-grade. The latter two were also among the five countries showing the weakest correlations with confidence.

Comparison between primary and secondary school students. As was in confidence, the overall effect size of interest turned out to be stronger at the secondary than primary school level. The country average correlation was greater at the eighth-grade level $(r=.276)$, compared to that at the fourth-grade level $(r=.185)$. The range of the five largest correlations fell between $r=.358$ and $r=.427$ at the eighth-grade level whereas it was between $r=.282$ and $r=.331$ at the fourth-grade level. Thus, the effect of interest on achievement was stronger among the secondary school students, a finding consistent with the confidence-achievement relationship.

\section{Sense of School Belonging and Mathematics Achievement}

Overall findings. There was no country showing that sense of belonging at school had a moderately strong relationship with mathematics achievement at the fourth-grade level. On the other hand, eight countries (18\%) showed moderately strong associations at the eighth-grade level. These findings are reflected in the average correlations across the countries: virtually zero correlation at the fourth-grade level $(r=.076)$ but a weak correlation at the eighth-grade level ( $r=.133)$.

Country-specific findings. Although sense of belonging was not a good predictor of mathematics achievement in almost all countries, several countries at the eighth-grade level showed the effect sizes greater than the cut-off point criterion of $r=.224$ : among them are United Arab Emirates $(r=.295)$, Australia $(r=.289)$, and England $(r=$ .269). On the other hand, the lowest correlations were observed mainly in the East European countries: Czech Republic, Serbia, Poland, and Slovak Republic at the fourth grade, and Middle-Eastern countries: Iran, Jordan, Turkey, and Morocco at the eighth grade. 
Table 5. Regression Analysis Reults Predicting Mathematics: Beta Standardized Coefficients (standard error, s.e.,) and R-squared: Total Sample and Countries showing the Highst Correlations between the Noncognigive Variables and Mathematics: TIMSS 2015

\begin{tabular}{|c|c|c|c|c|c|}
\hline \multirow[b]{2}{*}{ Independent variables } & \multicolumn{5}{|c|}{ Fourth grade } \\
\hline & Total sample & Korea & Japan & Turkey & South Africa \\
\hline Confidence in mathematics & $0.43(0.00)$ & $0.56(0.02)$ & $0.47(0.03)$ & $0.43(0.02)$ & $0.27(0.02)$ \\
\hline Interest in mathematics & $-0.08(0.00)$ & $-0.03(0.03)$ & $-0.06(0.03)$ & $-0.02(0.02)$ & $0.14(0.02)$ \\
\hline Sense of belonging & $-0.01(0.00)$ & $0.01(0.02)$ & $0.04(0.02)$ & $0.09(0.02)$ & $0.02(0.02)$ \\
\hline Being bullied at school & $0.05(0.00)$ & $-0.06(0.02)$ & $0.06(0.02)$ & $0.09(0.02)$ & $0.18(0.02)$ \\
\hline \multirow[t]{2}{*}{ R-squares } & $18 \%$ & $30 \%$ & $20 \%$ & $24 \%$ & $20 \%$ \\
\hline & \multicolumn{5}{|c|}{ Eighth grade } \\
\hline Independent variables & Total sample & Norway & Taipei & UAE & Egypt \\
\hline Confidence in mathematics & $0.43(0.00)$ & $0.63(0.02)$ & $0.45(0.02)$ & $0.40(0.01)$ & $0.29(0.02)$ \\
\hline Interest in mathematics & $-0.02(0.00)$ & $-0.01(0.02)$ & $0.08(0.03)$ & $-0.08(0.02)$ & $0.04(0.02)$ \\
\hline Sense of belonging & $0.04(0.00)$ & $0.01(0.02)$ & $0.05(0.02)$ & $0.28(0.02)$ & $-0.07(0.02)$ \\
\hline Being bullied at school & $0.02(0.00)$ & $-0.05(0.02)$ & $-0.01(0.02)$ & $0.05(0.01)$ & $0.21(0.02)$ \\
\hline R-squares & $21 \%$ & $38 \%$ & $28 \%$ & $22 \%$ & $16 \%$ \\
\hline
\end{tabular}

Notes. The four countries per grade were selected for illustrative purposes, because they had the highest correlation with mathematics, for each of the non-cognitive variable. The coefficients in bold indicate that the particular country were chosen in this table due to their highest bivariate correlation with mathematics achievement for that particular non-cognitive variable (see Table 4).

Comparison between primary and secondary school students. Although sense of belong was more strongly correlated with achievement at the eighth-grade level $(r=.133)$ than at the fourth-grade level $(r=.076)$, it was not a good predictor of mathematics for students across most countries.

\section{Experience of Being Bullied and Mathematics Achievement}

Overall findings. There were two countries at each grade level where less frequent experience of being bullying at school was moderately strongly and positively correlated with mathematics: South Africa $(r=.261)$ and Jordan $(r=$ $.224)$ at the fourth-grade and Egypt $(r=.262)$ and South Africa $(r=.226)$ and at the eighth-grade. In all the other countries, students' bullying at school did not turn out to be a predictor of student achievement in mathematics (see Table 3).

Country-specific findings. Countries with the strongest correlations of bullying were South Africa, Jordan, and Saudi Arabia at the fourth-grade level, and Egypt, South Africa, Lebanon, and Jordan at the eighth-grade level (Table 4). South Africa was among the countries with the largest effect sizes for bullying at both fourth- and eighthgrade levels.

Comparison between primary and secondary school students. Although the average effect size was slightly stronger at the fourth-grade level $(r=.113)$ than at the eighth-grade level $(r=.081)$, bullying was not a good predictor of student achievement in all but two countries at each grade level.

\section{Findings from Multiple Regression Analysis}

In the final set of analysis, multiple regression was performed with the four non-cognitive variables as the independent variables and mathematics scores as the dependent variable. Regression was run for each of the five plausible values of mathematics scores and the averages of the regression estimates were taken as the final estimates. Table 5 shows the regression results for the total sample (which is the average of the within-country estimates), and four countries per grade for an illustrative purpose. The countries were selected because they had the highest correlations between mathematics and each of the non-cognitive variables (coefficient in bold). For example, Korea at the fourth-grade level was chosen because of its highest correlation between confidence and mathematics across all countries; and Turkey was chosen because of its highest correlation between sense of belonging and mathematics across all countries, etc. Japan was chosen for its predictive validity of interest although it had the third largest correlation because Korea and South Africa were included in Table $\mathbf{5}$ for their correlations of confidence and bullying, respectively.

For the fourth-grade sample data (total), the regression model explained about $18 \%$ of the variance in students mathematics performance. It can be seen, though, that the explained variance was virtually all due to confidence $(\beta=.43)$, because the regression coefficients of the other three independent variables were nearly zero (see Table 5 ). The same pattern was shown in the sample of Korea (as expected because Korea had the strongest correlation of confidence), but also in Japan and Turkey (in spite of its bivariate correlations between interest and sense of belonging and mathematics, respectively). Only in South Africa, the coefficients for the other variables were not near zero including bullying $(\beta=.18)$ although its strongest predictor was still confidence $(\beta=.27)$. 
The regression results of the eighth-grade sample data mirrored the pattern of the results of the fourth-grade sample data. The regression model overall explained about $21 \%$ of the variance of mathematics achievement while virtually all prediction came from confidence $(\beta=.43)$ and the other three independent variables showed virtually zero coefficients (see the total sample, in Table 5). The results for Norway and Taipei were similar to the total sample results where the regression coefficient of interest, sense of belonging and bullying were hovering around zero. On the other hand, UAE and Egypt showed relatively stronger (compared to the total sample) effects of sense of belonging $(\beta=.28)$ and bullying $(\beta=.21)$, respectively, although these coefficients were still weaker than those associated with confidence $(\beta=.40$ in UAE and $\beta=.29$ in Egypt).

\section{DISCUSSIONS}

The purpose of the present study was to examine and compare cross-country predictive validities of the four non-cognitive variables (confidence, interest, sense of belonging and bullying) with respect to mathematics achievement for primary and secondary school students. The study addressed: (a) predictive superiority among the four variables (identifying non-cognitive variable(s) with the best predictability of mathematics achievement); (b) universal applicability (predictive validities across countries/regions/cultures); (c) country or regional specific relevance (identifying country/region with stronger and weaker predictive validities); and (d) developmental implication (differential effects of the non-cognitive variables on achievement in primary and secondary school students). Implications for each of the non-cognitive variables are further elaborated in the following sections.

\section{Confidence as a Universal Predictor of Mathematics}

Previous studies (Lee, 2009; Lee \& Stankov, 2013, 2016; Stankov, Lee, Luo, \& Hogan, 2012; Stankov \& Lee, 2014, $2015,2016,2017)$ have demonstrated that confidence was the best predictor of academic and other cognitive performance when considering a broad range of non-cognitive variables. The present study contributes to the existing literature on the confidence-achievement relationships in the following ways. First and most importantly, the present study lends strong support to universal relevance of confidence in predicting students' mathematics achievement by documenting its medium effect sizes in all 63 countries ( 55 countries at the fourth-grade and 44 countries at the eighth-grade). The finding is indeed remarkable, with some countries (e.g., Norway, Sweden) showing the correlations up to $r=.50$ s and $.60 \mathrm{~s}$ at the eighth-grade level.

Second, the present study noted the average correlation sizes of .30s and .40s of the TIMSS confidence scale. The strength of the relationship is close to that of self-efficacy in the work of Bandura $(1989,2012)$. As mentioned in the introduction, the TIMSS confidence scale conceptually tapped into self-concept (e.g., Marsh \& Craven, 2006; Marsh \& Shavelson, 1985), but demonstrated in the present study stronger effect sizes than the typical effect sizes often reported in the previous self-concept research $(r=$ mid .20s, see Stankov \& Lee, 2014). Out of more than 60 countries, one country demonstrated an effect size of greater than $r=.60$, which is about the effect size level of confidence in previous studies of Stankov and his associates (Stankov \& Crawford, 1997; Stankov \& Lee, 2015).

Third, while previous studies of the confidence-achievement relationships were mostly conducted with university or secondary-school students, the present study reported a similar result of confidence-achievement relationships among primary school students. Marsh, Ellis and Craven (2002) argued that self-concept in learning of an academic domain can be reliably measured among kids as young as 4 or 5 years old. Kleitman and Moscrop (2010) also claimed that a self-evaluative trait can be reliably measured among children aged 9 to 11. It is possible that young children's confidence in number/mathematics may emerge even before children's primary schooling.

\section{Developmental Implications of the Role of Interest for Mathematics Achievement}

The most notable finding of the interest-achievement relationship in this study was its stronger effects among the secondary school students (compared to that of primary school students). Denissen et al. (2007) reported that the associations were slightly over .30s for fourth-graders and reached almost .50s for eighth-graders, and demonstrated that the strength of associations increased as students moved onto the next level of schooling from grade 1 to 12. Critical times for interest development appeared between grades 1 to 9 as the associations slightly level off when students were in grade 10 and onwards. Both previous and our studies seem to suggest that as students have more experiences in schooling, self-awareness of their own interest may be intensified and the activities may be more focused based on their interest. In this light, possible early assessments and follow-up initiatives for mathematics learning may have to start earlier than the secondary school level, i.e., before students' interest in subject areas is set too firmly.

The present study also noted that East Asian countries ranked in the top five countries as having the strongest correlations with achievement at both fourth and eighth-grade levels (see Table 4). Ironically, Taipei, Korea and Japan were among the countries where students' reported interest in mathematics was the lowest at both fourth- 
grade level (Taipei - first, Korea - second, and Japan - fourth from the bottom among 55 countries/regions) and eighth-grade level (Korea - second, Japan - fourth, and Taipei - fifth from the bottom among 44 countries/regions). This finding is in agreement with previous studies (e.g., Marsh \& Hau, 2004; Frenzel, et al., 2007; Lee, 2009), claiming that East Asian students do not seem to possess healthy and positive psychological characteristics that are believed to be enablers of academic achievement (e.g., low self-concept, low self-efficacy, high anxiety, high negative emotions). The present study adds to the past research by demonstrating that the strength of relationships between interest and mathematics was strong in the East Asian region although their interest in mathematics was the lowest across countries. The pattern was identical at both primary and secondary school levels. Putting three pieces together (i.e., high performance, low interest, and strong interest-achievement relationship), interest appears to be a particularly relevant non-cognitive construct in the East Asian region. Although East Asian students in general do not like mathematics learning, those who like mathematics tend to learn better, study harder, and perform higher in mathematics. This type of cross-country evidence should be recognized and utilized in preparing educational policies to develop support strategies and measures to improve students' interest in mathematics in this region.

\section{Students' Sense of Belonging in the Anglo Culture}

Sense of belonging was a modest predictor of mathematics achievement at the eighth-grade level in only several countries/benchmarking partners: United Arab Emirates $(r=.295)$, Australia $(r=.289)$, England $(r=.269)$, Malta $(r$ $=.258)$, Hong Kong $(r=.233)$, and United States $(r=.228)$. The next three countries with the strongest correlations (although not shown in Table 4) were New Zealand $(r=.203)$, Canada (Quebec, $r=.202)$, and Ireland $(r=.196)$. With the only exception of United Arab Emirates, these countries belong to Anglo (Australia, England, United States, New Zealand, Canada, and Ireland) or former colonies of England (Malta, Hong Kong). Much of past research on sense of belonging at school has been conducted in the North American context (e.g., Fuller-Rowell \& Doan, 2010; Mattison \& Aber, 2007; Wang \& Hugely, 2012). The TIMSS data warrants further investigation to learn more about psychological mechanisms of sense of belonging in school in these countries. Ironically, from the individualism-collectivism cultural dimension perspective, sense of belonging has been more associated with collectivist than individualistic countries (House, et al., 2004), whereby a theoretical expectation would suggest otherwise.

Caution needs to be registered in that the similar pattern (i.e., strong Anglo country presence) was not found in PISA 2000 data (see Willms, 2003: Table 3.1). The sense of belonging measure produced nearly zero correlation with mathematics achievement for Anglo countries [Australia $(r=.01)$, England $(r=.06)$, New Zealand $(r=.03)$, Canada $(r=.02)$, and Ireland $(r=.00)]$ except for United States $(r=.15)$. The similar finding was obtained in our study at the fourth-grade level where no single country showed (at least moderately strong) predictive validity of sense of belonging. Possible reasons for this lack of associations might be that young students especially those in primary school may not have developed sense of belonging at school (a) because of insufficiency in self-identity development (Baumeister \& Leary, 1995) or maturity to place oneself in social-cognitive perspectives (Osterman, 2000), (b) because there are no substantial variations across schools within a country (Willms, 2003), or (c) because school/academic performance and sense of belonging at school are just two separate dimensions of students' lives at school. Given that only several countries showed modest correlations at the eighth-grade level in the TIMSS 2015, coupled with the PISA findings (Willms, 2003), the third conclusion seems to be most plausible except, perhaps, for a handful of Anglo countries.

\section{Bullying as an Issue in the Lower-Income Countries}

In spite of previous studies that argued for the significant link between students' bullying at school and their social-emotional and academic development (Craig, 1998; Roland \& Galloway, 2004; Schwartz et al., 2005), the present study showed that bullying was associated with student achievement only in a few countries: South Africa, Jordan, and Saudi Arabia at the fourth-grade, and Egypt and South Africa at the eight-grade (see Table 4). Relative lack of predictability of bullying for student achievement in most countries might be because bullying may not involve every student at school and/or because bullying incidences may not happen every day, unlike subject learning and teaching as regular classroom activities.

It is possible that bullying was a reasonably good predictor of student achievement in countries where bullying incidents occurred frequently. To check this idea, student reporting of experiences of bullying was examined in the TIMSS 2015 data, and the countries' raw scores on the bullying scale are presented (see Appendix 1) with the countries reporting more experiences of bullying placed on the left-side hand. It can be seen that students expressed having more frequent bullying incidents in South Africa, Egypt, and Saudi Arabia (mentioned above) along with other Middle-Eastern countries such as Bahrain, Qatar, Oman, Morocco, and Lebanon. Among them, South Africa stands out because bullying is clearly an issue for its prevalence (the first at the fourth-grade and the third at the 
Table 6. World Regions with the Strongest and Weakest Effect Sizes for Mathematics Achievement: TIMSS 2015

\begin{tabular}{|c|c|c|c|c|c|}
\hline \multicolumn{2}{|c|}{$\begin{array}{c}\text { Effects on Mathematics } \\
\text { Achievement }\end{array}$} & Confidence & Interest & Sense of Belonging & Bullying \\
\hline \multirow[b]{2}{*}{ Strongest } & 4th-grade & No particular region & East Asia & East Asia & Middle-East \\
\hline & 8th-grade & $\begin{array}{c}\text { Scandinavia } \\
\text { \& East Europe }\end{array}$ & Scandinavia \& East Asia & Anglo & Middle-East \\
\hline \multirow{2}{*}{ Weakest } & 4th-grade & $\begin{array}{c}\text { Middle-East \& } \\
\text { Southeast/Central Asia }\end{array}$ & Europe & East Europe & Middle-East \\
\hline & 8th-grade & $\begin{array}{c}\text { Southeast/Central Asia } \\
\text { \& Africa }\end{array}$ & Middle-East & Middle-East & East Asia \\
\hline
\end{tabular}

eighth-grade, see Appendix 1) and for its influence on student achievement (the first at the fourth-grade and the second at the eighth-grade, see Table 4 ).

Previous research has suggested that bullying happens more frequently in lower-SES schools or among students with lower family SES (Roland \& Galloway, 2004). The present study sheds further insight on cross-country implication indicating a tendency for more prevalence of and stronger effects of bullying on student achievement in less resourced and less developed world regions. It appears that considerable investment and explicit effort can be made by the international assessment communities to further explore and understand the nature, extent, and severity of this issue in the region.

\section{Limitation}

A few limitations of this study should also be mentioned. First, all students' responses were collected via selfreport of the Student Questionnaire. The unknown component in self-reporting includes truthfulness, trustworthiness, and accurate reporting of "true" attitudes or behaviors. Second, although the four non-cognitive variables loosely fit with the PSCF framework (Lee \& Shute, 2010), they were not a comprehensive set of students' non-cognitive attributes. Other scholarly work (e.g., Hattie, 2009; Lee \& Stankov, 2018) have complied more comprehensive lists of non-cognitive variables to explain student achievement. Third, the country-level crossage/cross-grade findings should be taken with caution because the groups of the participant countries were not identical between the two grade levels. Relative effects of non-cognitive variables on student achievement can be compared only in the countries that participated in both grade levels. Lastly, while the regression analysis confirmed the wash-out effect of the other non-cognitive variables due to the much stronger effect of confidence on student achievement, we highlighted on bivariate relationships between each of the non-cognitive variables and mathematics achievement because we believe that they better address the overall aims of the present study.

\section{Conclusion}

Universal predictability of confidence is indeed remarkable with $100 \%$ of countries in both grades showing at least a medium effect size for mathematics achievement. On the other hand, interest was a better predictor for secondary school students than it was for primary school students. Although belonging and bullying were not good predictors of mathematics, the issues about social acceptance and perhaps school violence will need to be carefully addressed among the small number of countries that did showed moderately strong associations with student achievement.

The present study highlights the pronounced regional ties of indicating particularly strong relationships between non-cognitive constructs and achievement (summarized in Table 6). For the Middle-Eastern and African region, bullying was a critical issue. For East Asian students, self-awareness of interest seems to be particularly relevant at both primary and secondary levels. For Anglo countries, sense of belonging exerted a strong effect on their secondary school students. Lastly, individual differences of confidence and interest appear to be relevant for academic achievement in Scandinavian countries. These unique regional findings provide an impetus for conducting future studies to gain a deeper understanding of macro- and micro-level factors associated with the non-cognitive variables examined in this study. For instance, what are the cultural/system-level characteristics that contribute to students in Anglo culture to perceive and value sense of belonging at school? Why is sense of belonging more strongly related to achievement in Anglo cultural group than in any other groups? What are the features of the East Asian societies and cultures that would motivate their students to be driven by their interest? What makes Scandinavian countries value confidence more strongly than other regional groups? The insight to be gained will be most effectively examined and managed in cross-national investigations across the world regions. 


\section{REFERENCES}

Babchishin, K. M., \& Helmus, L. M. (2016). The influence of base rates on correlations: An evaluation of proposed alternative effect sizes with real-world data. Behavior research methods, 48, 1021-1031. https:/ / doi.org/10.3758/s13428-015-0627-7

Bandura, A. (1989). Human agency in social cognitive theory. American psychologist, 44, 1175-1184. https://doi.org/10.1037/0003-066X.44.9.1175

Bandura, A. (2012). On the functional properties of perceived self-efficacy revisited. Journal of Management, 38, 9-44. https:/ / doi.org/10.1177/0149206311410606

Baumeister, R., \& Leary, M. R. (1995). The need to belong: Desire for interpersonal attachments as a fundamental human motivation. Psychological Bulletin, 117, 497-529. https:/ / doi.org/10.1037/0033-2909.117.3.497

Bong, M., \& Skaalvik, E. M. (2003). Academic self-concept and self-efficacy: How different are they really? Educational Psychology Review, 15, 1-40. https:/ / doi.org/10.1023/ A:1021302408382

Chen, X., Rubin, K. H., \& Li, D. (1997). Relation between academic achievement and social adjustment: Evidence from Chinese children. Developmental psychology, 33, 518-525. https:/ / doi.org/10.1037/0012-1649.33.3.518

Craig, W. M. (1998). The relationship among bullying, victimization, depression, anxiety, and aggression in elementary school children. Personality and Individual Differences, 24, 123-130. https:/ / doi.org/10.1016/S0191-8869(97)00145-1

Deci, E., \& Ryan, R. (1985). The general causality orientations scale: Self-determination in personality. Journal of Research in Personality, 19, 109-134. https:/ / doi.org/10.1016/0092-6566(85)90023-6

Denissen, J. J., Zarrett, N. R., \& Eccles, J. S. (2007). I like to do it, I'm able, and I know I am. Child Development, 78, 430-447. https:/ / doi.org/10.1111/j.1467-8624.2007.01007.x

Foy, P. (2017). TIMSS 2015 user guide for the international database. Chestnut Hill, MA: TIMSS \& PIRLS International Study Center, Boston College $\quad$ Retrieved from http:/ / timssandpirls.bc.edu/timss2015/international-database/downloads/T15_UserGuide.pdf

Frenzel, A. C., Thrash, T. M., Pekrun, R., \& Goetz, T. (2007). Achievement emotions in Germany and China: A crosscultural validation of the Academic Emotions Questionnaire-Mathematics. Journal of Cross-Cultural Psychology, 38(3), 302-309. https:/ / doi.org/10.1177/0022022107300276

Fuller-Rowell, T. E., \& Doan, S. N. (2010). The social costs of academic success across ethnic groups. Child development, 81, 1696-1713. https:// doi.org/10.1111/j.1467-8624.2010.01504.x

Gifford-Smith, M. E., \& Brownell, C. A. (2003). Childhood peer relationships: Social acceptance, friendships, and peer networks. Journal of school psychology, 41, 235-284. https:/ / doi.org/10.1016/S0022-4405(03)00048-7

Gottfried, A. E., Fleming, J. S., \& Gottfried, A. W. (2001). Continuity of academic intrinsic motivation from childhood through late adolescence: A longitudinal study. Journal of educational psychology, 93, 3-13. https:/ / doi.org/10.1037/0022-0663.93.1.3

Hattie, J. (2009). Visible learning: A synthesis of over 800 meta-analyses related to achievement. London: Routledge, Taylor and Francis Group.

Hoover, J. H., Oliver, R., \& Hazler, R. J. (1992). Bullying: Perceptions of adolescent victims in the Midwestern USA. School Psychology International, 13, 5-16. https:/ / doi.org/10.1177/0143034392131001

House, R. J., Hanges, P. J., Javidan, M., Dorfman, P. W., \& Gupta, V. (Eds.). (2004). Culture, leadership, and organizations: The GLOBE study of 62 societies. Sage publications.

Juvonen, J., Nixhina, A., \& Graham, S. (2000). Peer harassment, psychological adjustment, and school functioning in early adolescence. Journal of Educational Psychology, 92, 349-359. https://doi.org/10.1037/00220663.92.2.349

Kleitman, S., \& Moscrop, T. (2010). Self-confidence and academic achievements in primary-school children: Their relationships and links to parental bonds, intelligence, age, and gender. In A. Efklides, \& P. Misailidi (Eds.), Trends and prospects in metacognition research. Part 2 (pp. 293-326). New York: Springer, https://doi.org/10.1007/978-1-4419-6546-2_14

Krapp, A. (1999). Interest, motivation and learning: An educational-psychological perspective. European Journal of Psychology of Education, XIV, 23-40. https:/ / doi.org/10.1007/BF03173109

Lee, J. (2009). Universals and specifics of math self-concept, math self-efficacy, and math anxiety across 41 PISA 2003 participating countries. Learning and Individual Differences, 19, 355-365. https:/ / doi.org/10.1016/j.lindif.2008.10.009 
Lee, J., \& Durksen, T. L. (2018). Dimensions of academic interest among undergraduate students: passion, confidence, aspiration and self-expression. Educational Psychology, 38, 120-138. https:/ / doi.org/10.1080/01443410.2017.1342770

Lee, J., \& Shute, V. (2010). Personal and social-contextual factors in K-12 academic performance: An integrative perspective on student learning. Educational Psychologist, 45, 185-202. https:/ / doi.org/10.1080/00461520.2010.493471

Lee, J., \& Stankov, L. (2013). A higher-order factorial structure among fifteen major educational-psychological constructs. Learning and Individual Differences, 26, 119-130. https:/ / doi.org/10.1016/j.lindif.2013.05.004

Lee, J., \& Stankov, L. (2016). Non-cognitive influences on academic achievement: Evidence from PISA and TIMSS. In Khine, M. S. (Eds.), Non-cognitive factors and educational attainment (pp. 33-57). The Netherlands: Springer. https://doi.org/10.1007/978-94-6300-591-3_8

Lee, J., \& Stankov, L. (2018). Non-cognitive predictors of academic achievement: Evidence from TIMSS and PISA. Learning and Individual Differences, 65, 50-64. https:/ / doi.org/10.1016/j.lindif.2018.05.009

Marsh, H. W., \& Craven, R. G. (2006). Reciprocal effects of self-concept and performance from a multidimensional perspective: Beyond seductive pleasure and unidimensional perspectives. Perspectives on Psychological Science, 1, 133-163. https:/ / doi.org/10.1111/j.1745-6916.2006.00010.x

Marsh, H. W., \& Hau, K. T. (2004). Explaining paradoxical relations between academic self-concepts and achievements: Cross-cultural generalizability of the internal/external frame of reference predictions across 26 countries. Journal of Educational Psychology, 96(1), 56. https:/ / doi.org/10.1037/0022-0663.96.1.56

Marsh, H. W., \& Shavelson, R. (1985). Self-concept: Its multifaceted, hierarchical structure. Educational Psychologist, 20, 107-123. https://doi.org/10.1207/s15326985ep2003_1

Marsh, H. W., Ellis, L. A., \& Craven, R. G. (2002). How do preschool children feel about themselves? Unraveling measurement and multidimensional self-concept structure. Developmental psychology, 38, 376-393. https:/ / doi.org/10.1037/0012-1649.38.3.376

Martin, M.O., Mullis, I.V.S., \& Hooper, M. (Eds.). (2016). Methods and procedures in TIMSS 2015. Chestnut Hill, MA: TIMSS \& PIRLS International Study Center, Boston College. Retrieved from http:/ / timssandpirls.bc.edu/publications/timss/2015-methods.html

Mattison, E. ., \& Aber, M. S. (2007). Closing the achievement gap: the association of facial climate with achievement and behavioral outcomes. American Journal of Community Psychology, 40, 1-12. https://doi.org/10.1007/s10464-007-9128-x

McGill, M. M., Decker, A., McKlin, T., \& Haynie, K. (2019, February). A Gap Analysis of Noncognitive Constructs in Evaluation Instruments Designed for Computing Education. In Proceedings of the 50th ACM Technical Symposium on Computer Science Education (pp. 706-712). ACM. https:/ / doi.org/10.1145/3287324.3287362

Olweus, D. (1993). Bullying at school: What we know and what we can do. Oxford: Blackwell.

Olweus, D. (2005). A useful evaluation design, and effects of the Olweus Bullying Prevention Program. Psychology, Crime \& Law, 11, 389-402. https:/ / doi.org/10.1080/10683160500255471

Osterman, K. F. (2000). Students' need for belonging in the school community, Review of Educational Research, 70, 323-367. https:/ / doi.org/10.3102/00346543070003323

Putro, N. H. P. S., \& Lee, J. (2017). Reading interest in a digital age. Reading Psychology, 38, 778-807. https:// doi.org/10.1080/02702711.2017.1341966

Rice, M. E., \& Harris, G. T. (2005). Comparing effect sizes in follow-up studies: ROC Area, Cohen's d, and r. Law and human behavior, 29, 615-620. https:/ / doi.org/10.1007/s10979-005-6832-7

Richardson, M., Abraham, C., \& Bond, R. (2012). Psychological correlates of university students' academic performance: A systematic review and meta-analysis. Psychological Bulletin, 138, 353-387. https:/ / doi.org/10.1037/a0026838

Rigby, K. (1997). Bullying in schools and what to do about it. Melbourne, Australia: Australian Council for Educational Research.

Roland, E. \& Galloway, D. (2004). Professional cultures in schools with high and low rates of bullying. School Effectiveness and School Improvement, 15(3-4), 241-260. https:/ / doi.org/10.1080/09243450512331383202

Roland, E. (2000). Bullying in school: Three national innovations in Norwegian schools in 15 years. Aggressive Behavior, 26, 135-143. https:/ / doi.org/10.1002/(SICI)1098-2337(2000)26:1<135::AID-AB11>3.0.CO;2-3

Schwartz, D., Gorman, A. H., Nakamoto, J., \& Toblin, R. L. (2005). Victimization in the peer group and children's academic functioning. Journal of Educational Psychology, 97, 425. https:/ / doi.org/10.1037/0022-0663.97.3.425 
Sheldon, S. B. (2003). Linking school-family-community partnerships in urban elementary schools to student achievement on state tests. The Urban Review, 35, 149-165. https:/ / doi.org/10.1023/ A:1023713829693

Stankov, L. \& Crawford, J. (1997) Self-confidence and performance on cognitive tests. Intelligence, 25, 93-109. https:/ / doi.org/10.1016/S0160-2896(97)90047-7

Stankov, L., \& Lee, J. (2014). Quest for the best noncognitive predictor of academic achievement. Educational Psychology: An international journal of experimental educational psychology, 34, 1-8. https:/ / doi.org/10.1080/01443410.2013.858908

Stankov, L., Lee, J., Luo, W., \& Hogan, D. (2012). Confidence: A better predictor of academic achievement than selfefficacy, self-concept and anxiety? Learning and Individual Differences, 22, 747-758. https:/ / doi.org/10.1016/j.lindif.2012.05.013

Stankov, L., \& Lee, J. (2015). Confidence and self-efficacy: Are they different? In Guay, F., McInerney, D., Craven, R., \& Marsh, H. (Eds.), Self-concept, motivation and identity: Underpinning success with research and practice (pp. 225-248). Charlotte, NC: Information Age Publishing.

Stankov, L., \& Lee, J. (2016). Quest for the best non-cognitive predictor of academic achievement. In Lee, J., \& Stankov, L. (Eds.), Noncognitive psychological processes and academic achievement (pp. 1-8). Oxon, UK: Routledge.

Stankov, L., \& Lee, J. (2017). Self-beliefs: Strong correlates of mathematics achievement and intelligence. Intelligence, 61, 11-16. https:// doi.org/10.1016/j.intell.2016.12.001

Vansteenkiste, M., Lens, W., \& Deci, E. L. (2006). Intrinsic versus extrinsic goal contents in self-determination theory: Another look at the quality of academic motivation. Educational Psychologist, 41, 19-31. https://doi.org/10.1207/s15326985ep4101_4

Wang, M-T., \& Degol, J. L. (2016). School climate: A review of the construct, measurement, and impact on student outcomes. Educational Psychology Review, 28, 315-352. https://doi.org/10.1007/s10648-015-9319-1

Wang, M-T., \& Hugule, J. P. (2012). Parental racial socialization as a moderator of the effects of facial discrimination on educational success among African American adolescents. Child Development, 83, 1716-1731. https:/ / doi.org/10.1111/j.1467-8624.2012.01808.x

Wentzel, K. R. (1994). Relations of social goal pursuit to social acceptance, classroom behavior, and perceived social support. Journal of Educational Psychology, 86, 173-182. https://doi.org/10.1037/0022-0663.86.2.173

Willms, J. D. (2003). Student engagement at school: A sense of belonging and participation. Results from PISA 2000. Paris: OECD.

Yoneyama, S., \& Naito, A. (2003). Problems with the paradigm: The school as a factor in understanding bullying (with special reference to Japan). British Journal of Sociology of Education, 24, 315-330. https:/ / doi.org/10.1080/01425690301894 


\section{APPENDIX 1}

No experience of being bullied: 4th-grade in TIMSS 2015

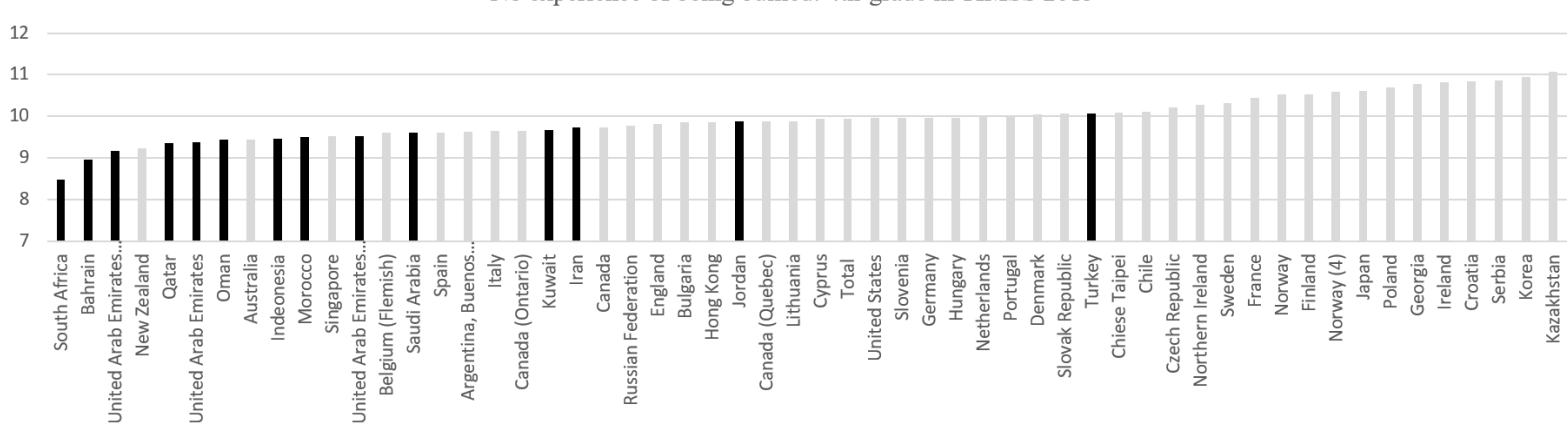

No experience of being bullied: 8th-grade in TIMSS 2015

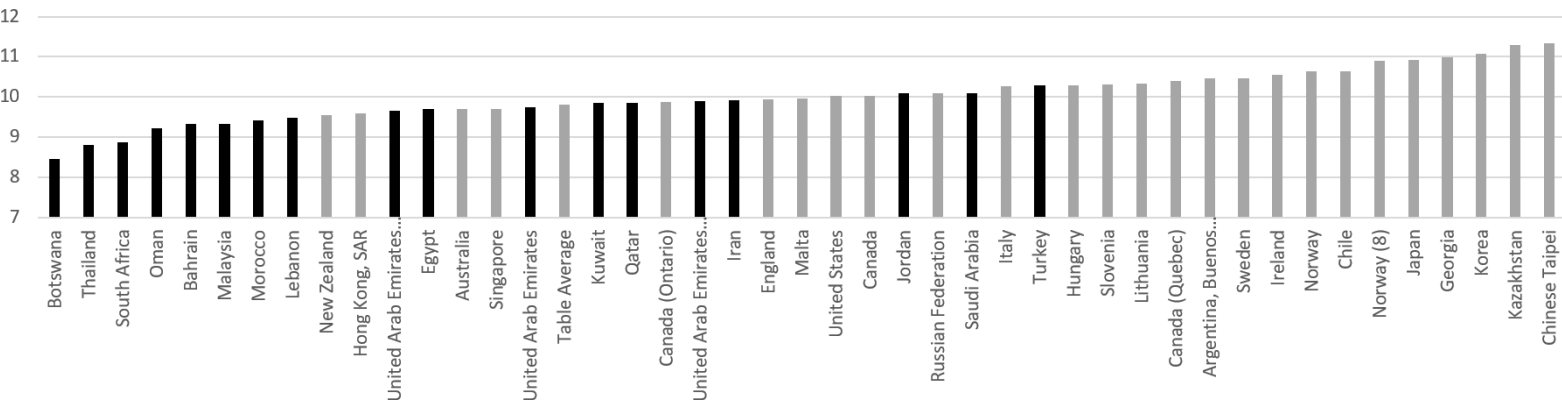

http://www.ejmste.com 